\title{
Leadership in research across academia and practice
}

\author{
John McRae \\ University of Tennessee, Knoxville, Tennessee
}

I value very much the award and I certainly have truly enjoyed the time and the meeting these couple of days has been extremely stimulating. We were talking several of us ahead of time about the rigor and the intensity with which the programs are being presented in each of the meetings. We really, I think, have the group here that's going to be serving us well for the future.

I want to also say today, in expressing my appreciation for this award, that the list of past awardees is stellar and includes several colleagues and personal friends to whom I owe a debt in my professional development and am grateful for the opportunity to address the conference and hope that my remarks with be of even a small benefit to our collective efforts to strengthen research across academia and practice.

I started my career in both academia and practice in 1967, little more than the 30 years you were so gracious to give me, in Gainesville and at the University of Florida. Over this span of the last 42 years I have sought to develop my own research and creative work agenda and, through administrative roles, have made an effort to foster the research of colleagues when I could. So what was it like in the late 60's and early 70's? Some of you may recall. In the interest of full disclosure, I have included a few images of my research work during my early years as a faculty member at the University of Florida. And so, here is another shot of our research team. Some of you may remember the Chicago 7 . This is the rainbow 9 and, in fact, aside from myself, whom you will recognize, there are several other people there who are today in positions helping to lead this nation. That is kind of hard to imagine but there they are.

So what was going on in architectural education, technology and practice at that time 40 years ago? Certainly, we were just on the cusp of the personal computer age, and I included this list of a few items that help us walk down memory lane. Highlights of which show not only where we were but how far we've come. Marshall McLuhan telling us we're going at 90 miles an hour down the road looking in the rearview mirror. The Princeton report which lead us to the $4+2$ programs and of course amazing leaders like Buckminster Fuller and lan McHarg who were telling us things that we should have listened more to. My first grant of any consequence was a $\$ 25,000$ award from the National Endowment for the Arts in 1970, to make a comparative study in space simulation across three mediums, still photography, video and film, and how these could be used effectively by teachers and parishioners during the project design phase. My co investigator was Larry Peterson, one of the people in one of those earlier shots, and our cross collaborator was Tom Pugh, and I know a lot of you know Eaton from ARCC, and both of whom have had distinguished careers. Looking back, for me this project is a dramatic demonstration of just how far we have come technologically in the last 40 years. This is the point at which I would also like to mention the crucial value of mentors and others who have had an impact on our research and our growth as scholars and I think that we would all agree. In my own professional life the list is long but it includes names that some of you may recognize: Bob Harris, Joe Sabatella, Leland Shaw, Sandra Howell, Joe Bilello, Robert Ivy, Lee Mitgang, John Eberhart, and of course my good friend Richard Hayes there at the back whom l've appreciated so much having as a friend and mentor in certain areas of my work. And I know that we all have people that we could point to in that way.

While my first project focused on technology and space simulation, the main thrust of my research, as mentioned by Michel, was focused on gerontology and k-12 education. Working at these two ends of the life spectrum has been very rewarding, where l've been primarily engaged in the area of housing for the elderly, on the one hand, along with seeking more effective ways to introduce natural and built environment issues to elementary school children. This definition was actually developed jointly in 1999 by ARCC together with ACSA and AIA as part of the former initiative for architectural research. I will not read the whole thing but you can see the range of areas that are covered in this and the important value of a method of inquiry. There are three points mentioned in reference to this at the bottom that these architectural efforts are those that are clearly identifiable goals of course one follows a creditable systematic method and the process has significant results in a documented manner. I think it should also be pointed out that design exploration certainly can be a form of research inquiry if it incorporates the three characteristics listed above. We all talked about that as well in the session yesterday. 
Another simple definition might be to conduct research, or work, through the discovery of knowledge that can be quantified and replicated, thereby increasing the value of design to society.

So where are we today? Within the architectural profession and architectural education, there is an urgent need to conduct substantive research to favorably affect the quality of the built environment and its relationship to the natural environment. More than ever, there is a critical need for generating, codifying and sharing knowledge. This situation, while a growing need, is not a new dilemma. Historically, limited value has been placed on architectural research by academia, the profession, or society in general. Schools of architecture have struggled with developing substantive research agendas, and practitioners have done very little and society in general does not consider our profession to have any real focused research agenda. However, as mentioned previously in the conference, significant research advances in such fields as engineering, medicine, and aerospace have contributed enormously to the ability of professionals in these fields to affect quality of life issues and society in general. Mechanisms are in place within these professions for generating, codifying, and sharing knowledge in a consistent manner linking academia and practice effectively. The profession of architecture, which does not have a strong history of research, must take similar action. Ironically, of all the professions, architecture, perhaps similar to medicine, serves a need, which literally penetrates every pore of a persons' life from the ordinary to the sublime. The impart of architecture was aptly stated in the BoyerMitgang report: Building Community: A New Future for Architectural Education and Practice from the mid 90's, with this statement: "Never in history have the talents, skills, and broad vision of the architectural profession been more urgently needed. Name any significant environmental, social, political, or economic challenge facing the nation and lurking in the background, hardly noticed and rarely discussed, is the arcane matter of architecture." This was pointed out to us again yesterday in Dr. Luebkeman's address when he used examples such as energy consumption studies statistics that have been developed with the respect to building construction. Along with the afore mentioned pervasive nature of architecture, there are a growing number of research opportunities and challenges facing the profession today. This dialogue is being framed by numerous leaders in an effort to position education and its practice to respond effectively. The solution to the dilemma lies within our ability to properly analyze the situation and act accordingly. Tom Fisher, Dean of the College of Architecture and Landscape Architecture at the University of Minnesota, has recommended several strategies in an address he gave years ago to the AIA board of directors, titled: "The Once and Future Profession of Architecture". Dean Fisher outlined three pairs of strategies, all of which effect research. Fisher stated:

\begin{abstract}
"The first pair involves rediscovering our public calling and expanding the range and types of services we offer and educate for. The second pair involves asserting our economic value and exploring new ways of generating and distributing knowledge. We need as practitioners and educators to join in a common research effort to build a knowledge based on the effects of what we do. Practitioners do not have a good way of communicating to the schools nor do the schools have a good way of capturing the knowledge that we need to generate or of communicating relevant research findings back to the profession. The final pair of strategies involves redefining our core skills and embracing a wider application of our knowledge at the edges of the profession".
\end{abstract}

Fisher's words presented a clear overview of the situation both in architecture and in practice generally. His address was quite instrumental in the AIA forward to its present stronger focus on knowledge communities and the knowledge boards programs. So again, where are we today? How is our world different from the time of my first grant focused on technology the year the earth day was started (April $22^{\text {nd }}$ ), a little less than a week from now actually. I believe that two of the most significant differences in both architectural education and practice are technological changes and the pervasive focus on sustainability and effective energy use. Both of these areas are having an enormous positive impact on both education and in practice. BIM and integrated project delivery for instance are creating entirely new platforms for collaboration and project effectiveness while sustainability is becoming a part of the DNA of design and construction. There are obvious cautions, the sort of tail wagging the dog and so forth, but overall the change is significant. Along with this, an integrated approach to shared knowledge across the boundaries of education and practice is at our fingertips. Mechanisms are being put in place in an effort to develop substantial means for shared knowledge. An example of this is in the increased focus in recent years on evidence-based design, often more referred to in the health care sector. It is an exciting time in this bridge across education and practice. All of our organizations: ACSA, ARCC, AIA, SBSE and so forth are all involved in some way to foster research across boundaries and establish means for sharing. We also have the AIA knowledge communities I mentioned, the UC Berkeley $\mathrm{PhD}$ database, the interior design repository from the University of Minnesota, the solar decathlon program of course and like those that were mentioned earlier the NCARB prize, the Upjohn awards also discussed, Rafael Vinoly fellowships to name a few as well as of course the active research by people even in this room obviously. To this must be added the work of those outside our field but closely tied, researchers such as Fred Gage, and Richard Jackson. We must also include the work of the students themselves. Building a culture of research among undergraduates and graduates is crucial to the future of our profession. By way of example, our own University has an undergraduate research awards program entitled with the appropriate acronym EUReCA: The Exhibition of Undergraduate Research and Creative Achievement. 
This year a team from the college received the top award university wide. This project, with an interdisciplinary team of consultants, is also entered in a design competition sponsored by EPA, which as we speak is being set up on the mall, as sort of EPA's answer to the solar decathlon.

However, even with all of this we are somewhat stuck and have not moved very far. How are we stuck? first it could go without saying that there is still very little funding for design related research at the national level. We are all familiar with the appalling low percentage of federal funding and even less specifically goes towards research in architecture and environmental design. USGBC has just finished another study on that and the numbers almost off the bottom of the chart. The newly initiated National Academy of Environmental Design as mentioned earlier will also provide inroads at this level those involved will be helping us to get recognition with the national research council and other effective ways that we can move the agenda forward. Of course, there are also limited ways for sharing knowledge across fields, they are still limited. The LEED program is an important example in one area of our field where substantial inroads are being made. We should be reminded that the architecture profession was late into the game with LEED, having resisted in taking leadership role early on. If I'm not mistaken there was a time early in the development USGBC that there was not a single architect on the leadership board maybe someone will correct me later. As a result, architects have had their concern shaped by others to a large extent with regard to LEED. Aside from technological advances, LEED may be considered by some to be the single biggest substantial change impacting architects and buildings since ADA and we have been on the outside looking in.

Another factor keeping us stuck is the intense culture of proprietary knowledge among architects. For over a decade the ASCA and the AIA have collaborated on development of case studies pre and post occupancy analysis by students and faculty of numerous projects across the US. Valuable collaborations have been developed for utilizing these case studies as elements of inter-programs and in other ways. The studies of course while excellent invariably fall short of what is needed because of the desire on the part of firms to withhold key information related to cost, design and technology innovations. As mentioned earlier the fields of medicine and engineering have advanced much further in these mechanisms to share success and failure alike. We have all used the example of how new breakthroughs on problems are reported openly in the New England Journal of Medicine or other publications. Engineering similarly has a strong peer review for virtually all of its work and advances. How many times have you heard someone say: what we need in architecture is the equivalent of the teaching hospital?. That's true, the concept would be valuable and concerted efforts have been made to establish a teaching office approach. Ten years ago during the first internship summit at Shaker village a significant effort was made to put forward a strategy for a more seamless transition between education and practice. The practice academy concept is one thing that came out of that and we're still working on this.

You say, how does this relate to issue of research? in several important ways, because what is needed in both our schools and practice, but particularly in practice, is a cultural shift, a sea change literally of developing and utilizing legitimate research and collaboration with schools. We are all aware that architectural programs of varying degrees substantial research are underway for decades. It has not, however, consistently made its way into practice and firms themselves have not been engaged in research in effective ways other than ad hoc and isolated examples. As mentioned earlier I served for two years from 2003 to 2005 as senior director of grants and development for the national AIA. At this point my colleague Richard Hayes should be up here talking but in helping to guide the research initiatives and directions of the institute during that time we, himself included, made a concerted effort to build stronger research bridges across academia and practice. It was rewarding to have a roll and initiating the first set of RFP's for seed funding to schools and faculty distributed in the winter of 2004. During this time we worked to set directions for the future including a recommendation to the AIA board that a substantial endowment be set aside from AIA funds for similar seed research projects. Subsequently this approach was adopted and the Upjohn research awards had been established through and endowment. At that time we also established at AIA both short and long term goals including an over the horizon goal to develop a fully integrated approach to generating codifying and sharing knowledge. Most of you are familiar with AIA knowledge communities within AIA. There are presently 18 such knowledge communities or focus areas as one of our goals was to develop a coordinated approach to research among and on behalf of these communities. A few of them, such as the healthcare group, have established long term and effective research agendas. As part of our work there, we established broad spheres of research and sought to link with the knowledge communities and potential topics. The following chart describes eight areas of research identified at the time from a survey of practitioners through leaders and university experts from across the country. These areas are still relevant today and I'm not speaking as a member of the staff any longer of AIA but I think that they still have a good fit. These are sustainability and energy, design, project delivery, community development, materials/methods and technology associated, building performance, culture and the condition of the profession and user needs and client groups.

I would like to briefly highlight each of these research areas and their links to the knowledge communities and I also want to point out the crucial importance of linking 
these to topics and funding opportunities, especially within federal sources including NSF and others. The current availability of stimulus funding for a short time further heightens the urgency of aligning the research within the established guidelines for such funding. So I'll just take a moment for each one, l'll not dwell on each. Sustainability and energy, the way in which the natural and built environments are connected through a holistic sustainable approach to design and construction. Out to this right side there really should be another column of those most current research opportunities, the RFP's and other ways in which funding is laid out by the federal government to help in sort of getting connections across there and then the appropriate universities that can work together with them. Of course design, the process of developing innovative and creative solutions to human need. All of you know from the neuroscience exploration mentioned at the top the academy for neuroscience for architecture. Entities like that will make a difference to us. Project delivery, the process through which design are brought to fruition. There is a very worthwhile effort that's been done recently in the area of integrated project delivery and a joint effort by Autodesk, HOK, and others and I think that's online and available for people to look more at them. Community development, this of course is one of the areas, which will be huge as we begin to come out of the economic slump that we are in. Materials/methods and technology, this is another one that's going to be very important as we move toward the future, the products and technologies and support of design. In our own university, we are just starting a smart structures laboratory for instance and I'm sure that many of you already have things like that underway certainly maybe more than we do. Building performance and one that is not on this slide but should be is certainly commissioning, that is so important to the way in which we bring our buildings into a point where they are going to be effectively used by the owners. The culture and condition of the profession, and global practice right at the top of course and all the things that are listed down the way begin to show us. These are not of course in any way intended to be exhaustive topics but simply to give an impression of the possibilities. Then the last one, human user needs and client groups. The eight areas identified and the majors serve as a preliminary target area and while not limited gave focus to the RFP's program reinforcing the value or research and shared knowledge across the communities.

Another aspect of shared knowledge underway during my tenure at AIA was the initiative of the e-knowledge program. This area is currently designated on the AIA website as AKR: Architects Knowledge Resource. And again I mentioned Richard who's in charge of that particular area. It's a regularly updated section of the website dedicated to research and related topics. The intention is to eventually develop a highly interactive database and network to others across the country that is capable of providing substantive instant feedback on all topics of interest. This project, while still in the developmental stage will prove great value to practitioners and educators. Shown here is an interactive website you may be familiar with out of the McCord Museum of Archeology in Canada and it was one of those being looked at when we were discussing this.

I would like now to shift my attention to some specific examples as I move towards the latter part of my talk. While we obviously still have a long way to go in developing a coordinated means for sharing knowledge there are certainly ways that we've seen a lot going on. In the interest of time, l'm going to mention a few examples certainly there've been many others already talked about in the conference here today. The ones I'm going to highlight are largely form practice and you will likely know about most of them, perhaps some of you will know about all but they are worth highlighting. Many of you know Professor Renee Chang, University of Minnesota who through her work is quite knowledgeable about firms across the country and she suggests that there really are probably four categories, maybe more, of a research activity associated with firms. She says, you could line them up according to large firms with directors of research and I did some background on several of these, of course the usual suspects in many cases, Gensler, HOK, OWP/P, Perkins+Will , and so forth; and firms that bill research in as a percentage of their profits; and then the third one would be firms that have self awareness and incorporate internal education or grants related to research and practice. The firm that I was associated with before getting back into academia, RTKL, was one such firm and I thought it was working well there. The fourth is small firms that are so experimental that they need to do research just to accomplish their activity. So let us take just a quick look at a few of these examples. One that you certainly know about already, Kieran Timberlake, has received a great deal of well deserved exposure over the last several years through their emphasis on research in the office particularly as related to building technologies. Their work and approach, detailed in the inaugural Benjamin Latrobe fellowship from the AlA's College of fellows in 2001, was published in a book, Refabricating architecture in 2003. The firm has 10 or more active research studies underway and a dedicated staff of 4 . So these projects are listed that they're currently working on ranging across several areas but all technologically connected, advanced materials, fabrication and so forth. The firm looked inside academia to bring on board its first full time director of research; I'm sure a colleague of several of you, Billie Faircloth, formerly a faculty member at the University of Texas in Austin, who's been in this role for 8 months. In a conversation with Ms. Faircloth she revealed that the research staff also includes an environmental management expert, a sculpture, and a trained architect with a bend towards design. This team is focused on asking questions that address practice, exploring materials and technology and developing prototypes.

Form my own limited assessment; Kieran Timberlake is 
certainly one of the few firms taking this approach and including a dedication of up to four percent of its profits for research and exploration apart from billable projects. And this conversation was a recent one and in the economic down turn, they haven't changed that yet.

So next, The Center for the Built Environment, as part of UC Berkeley was started 12 years ago through a team effort of university, government and industry leaders with a focus on the challenge of improving the performance of commercial buildings. And you see these four categories that they're connected with and among the many projects the CBE has been engaged in, the most prominent recent one is the 52 story headquarters for the New York Times designed by Renzo Piano Building Workshop with a project team that included CBE, Flack+ Kurtz and Gensler. the building incorporates numerous technological innovations. The CBE and Laurence Berkeley National Labs contributed to commissioning and to developing and testing integrated shaded and lighting controls among other elements. This kind of active collaboration across practice and a university research center with government research funding from several sources contributed to important and new shared knowledge in the field using public money and the results were made public as well.

The Center for Building Performance, this outstanding project and facility at Carnegie Mellon has been developed over several decades by professor Vivian Loftness and her colleagues. I, like a number of you, have had the opportunity to visit this facility which is part of the college of architecture there. Truly a living laboratory building innovation with a focus on high performance office environments and working with DOE, GSA, NSF and the private sector, including architectural firms and companies such as Steelcase and Johnson controls. I found, by visiting the center and understanding more about the projects, that the research is certainly some of the most significant in the country relative to the work environment. What is being tested is the optimal work environment, one that maximizes worker health and productivity, flexibility and so forth. So in response to requests of wide spread problem of first cost, decision making, Loftness helped spearhead the building investment design support system bids tool. This was also, as you might have noticed in a quick scan, one of the projects which was first funded during the RFP studies back in 2004. Loftness said the results of these continuing efforts helped to show that better buildings are worth it.

Rafael Vinoly Architects is another one that has received prominence in the last few years. These programs begun in 2005 and were aimed at generating architectural knowledge that is informed by practice yet exceeds the limits of commission work. The research components seek to expand the boundaries of design and practice by offering financial grants and technological support for individual research. There were over 180 proposals this past year from 39 countries with 4 fellowships awarded for this year. I'm sad to say that one of our teams was only a finalist and we weren't among the 4 but certainly all those are congratulated. $\$ 160,000$ in cash and in-kind support. The partnerships included university, firm and industry collaboration and they are going to publish these results in 2010. An offshoot of this study, a previous project from 2005, is a study entitled From Industrial Insulation to a Roof Top Learning Landscape in the Bronx: the Stevenson Green Roof Project. Joe Hagerman the architect who at the time was a graduate student at Columbia University Engineering program now has after $31 / 2$ years has his work coming close to fruition. Rafael Vinoly is leading a public/private consortium to demonstrate the technological innovations in the roof of this school, a facility in south Bronx with a campus that includes 7 different schools.

I mentioned Renee Chang earlier; collaborators Renee Chang at Minnesota and Laura Lee in Carnegie Mellon are two architecture professors of note who have spent a great deal of time over a number of years focusing in their work of the need for research collaboration across academia and practice. They have, at their respective institutions and through the work of students, documented many case studies that have integrated design with emerging technologies. Professor Chang has tried several large scale projects by Frank Gehry and Associates as well as smaller scale work by a range of different firms. Lee and Chang collectively have had contact with a broad array of firms nationally and internationally and are involved in an ongoing effort with several organizations to foster these partnerships. Among them. Case; The Center for Architecture, Science and Ecology, a collaboration of S.O.M. and Rensselaer Polytechnic Institute, was launched this past fall, 2008. The Center, housed in the heart of Manhattan at Seven World Trade Center, is an innovative collaboration that engages scientists, engineers and architects from the professional and academic worlds toward a common goal of redefining how we build sustainable cities and environments. Rensselaer School of Architecture is heavily involved and has framed its advanced degree program and built ecologies around CASE. Research in this new program focuses largely on the development of innovative systems and materials that will shift building performance towards sustainable and energy self sufficient models, and has already received funding from DOE, NSF and other major state and federal sources.

As I conclude, let me reaffirm that there is a wide range of highly effective and collaborative university and architecture research centers operating on our campuses. I have touched on only a few. In fact, nearly every program in the country has some form of research center or mechanism for laboratory activity. I'm sure UT San Antonio does as well. I certainly know Austin right up the road does. Also, the Auburn Rural Studio, Texas A\&M center for health systems in design, the Georgia Tech's AEC integration laboratory and on it 
goes. There are programs like that in literally almost every college in the country. There are obviously so many other efforts that bear attention, and I urge our leadership to continue this effort toward innovation and shared knowledge trough collaboration. It will have a powerful impact on our ability as educators and practitioners to effect positive change on our environment and in a substantial way.

I close with these questions and ask that we challenge ourselves to press forward to the next level of integrating and sharing the knowledge. What strategies can be utilized to facilitate proactive research collaboration between practice and education? What are the impediments and the roadblocks to effective research collaboration? And what programs and specific research hold the most promise for impacting practice? We can talk about that some more during the remainder of the conference. I thank you for the opportunity tonight and I leave you with this quote that I think bears a little bit on what we're talking about. I want to stay as close to the edge as I can without going over. Out on the edge you can see all kinds of things you can't see from the center. Thank you very much. 